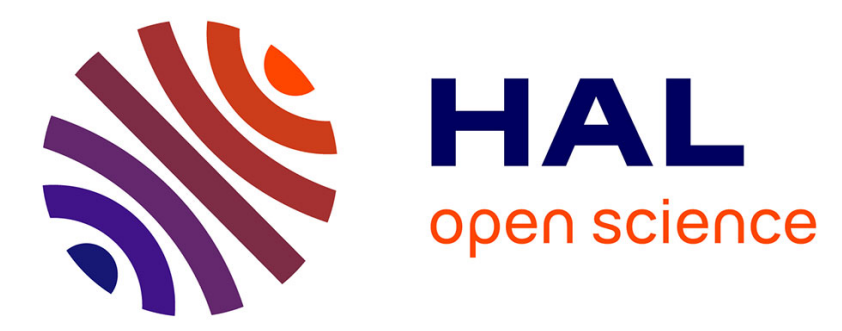

\title{
Ethical issues arising from the requirement to provide written information in palliative care.
}

Isabelle Plu, Grégoire Moutel, Irène Purssell-François, Nathanaël Lapidus, Françoise Ellien, Cécile Manaouil, Christian Hervé

\section{- To cite this version:}

Isabelle Plu, Grégoire Moutel, Irène Purssell-François, Nathanaël Lapidus, Françoise Ellien, et al.. Ethical issues arising from the requirement to provide written information in palliative care.. Palliat Med, 2007, 21 (1), pp.55-57. 10.1177/0269216306073699 . inserm-00123318

\section{HAL Id: inserm-00123318 https://www.hal.inserm.fr/inserm-00123318}

Submitted on 9 Jan 2007

HAL is a multi-disciplinary open access archive for the deposit and dissemination of scientific research documents, whether they are published or not. The documents may come from teaching and research institutions in France or abroad, or from public or private research centers.
L'archive ouverte pluridisciplinaire HAL, est destinée au dépôt et à la diffusion de documents scientifiques de niveau recherche, publiés ou non, émanant des établissements d'enseignement et de recherche français ou étrangers, des laboratoires publics ou privés. 


\section{Ethical issues arising from the requirement to provide written information in palliative care}

\section{Plu I, Moutel G, Purssell-Pursell I, Lapidus N, Ellien F, Manaouil C, Hervé C}

With the help of the Soins Palliatifs Essonne Sud Network

${ }^{1}$ Service de Médecine Légale, Hôpital Général, Centre Hospitalo-universitaire, 3 rue du Faubourg Raines, BP 1519, 21033 Dijon Cedex, France,

${ }^{2}$ Laboratoire d'Ethique Médicale et de Médecine Légale, Faculté de Médecine, Université Paris V René Descartes, 45 rue des Saints Pères, 75006 Paris, France

${ }^{3}$ IIREB, Institut International de Recherche en Bioéthique, Faculté de Médecine, Université Paris V René Descartes, 45 rue des Saints Pères, 75006 Paris, France

${ }^{4}$ Consultation de Médecine Légale, CHU, place Victor Pauchet, 80054 Amiens cedex 1, France

\section{Author for correspondence:}

Isabelle Plu, MD.

Service de Médecine Légale, Hôpital Général, Centre Hospitalo-universitaire, 3 rue du Faubourg Raines, BP 1519, 21033 Dijon Cedex, France

Tel. / Fax: +33 (0) 380293916

E-mail address: isabelle.plu@chu-dijon.fr 


\section{Abstract}

French Healthcare Networks aim to help healthcare workers to take care of patients by improving cooperation, coordination and the continuity of care. When applied to palliative care in the home, they facilitate overall care including medical, social and psychological aspects. French legislation in 2002 required that an information document explaining the functioning of the Network should be given to patients when they enter a Healthcare Network. Ethical problems arise from this legislation with regard to providing terminal patients with explicit information upon their entry into the palliative phase of the disease, and requiring them to sign the document. It highlights the limitations of this practice and the gap between the legislation and the nature of the physician-patient relationship in palliative care.

Key words: palliative care, healthcare networks, informed consent, ethics, physician patient relationship. 


\section{Palliative care in Healthcare Networks}

In France, Healthcare Networks first appeared in the 1980s with the emergence of AIDS, a disease that requires co-ordinated, multidisciplinary care. These Networks arose thanks to the voluntary efforts of a few healthcare professionals, independently of regulations and institutional wishes. Regulations concerning these Networks have been in force since 1996.

The aim of Healthcare Networks is to improve the care received by patients, by improving coordination, communication and partnerships between healthcare professionals. They improve the continuity of treatment, facilitate management of the multidisciplinary healthcare acts and ensure that each patient's diseases are considered together. French Healthcare Networks bring together several healthcare professionals, who decide to work in a fixed geographical area, around a particular medical problem, such as asthma, AIDS, care of the elderly, obesity, diabetes or palliative care. The professionals are more often nurses and doctors, but they may be psychologists, physiotherapists, pharmacists and social workers. Usually, they work in the community in order to provide care at home, often in collaboration with hospital professionals.

Palliative care was a pioneering field in Healthcare Networks because it required a multidisciplinary approach involving medical, social and psychological care. Within a Healthcare Network, palliative carers were able to consider the needs and requests of patients in the final stage of life and those of their families.

However, regulations such as the obligation to obtain informed consent, which apply to all types of Healthcare Networks seem to be difficult to apply in palliative care Networks because of the specific nature of the management of patients in the final stages of life. 


\section{Legal aspects of patient information and consent in palliative care}

In the French healthcare system, doctors are obliged to inform patients of their state of health, their therapeutic options and the risks of each option, and to obtain consent for treatment. This information is traditionally provided orally. This consent is considered tacit as soon as the patient accepts medical care. Before 2002, written consent was obtained only in cases that were considered particularly sensitive (genetic tests, medically assisted reproduction, abortion, clinical research etc.).

In recent years, there has been an increasing social demand from patients for more information in order to give enlightened consent before entering any healthcare institution. Similarly, when patients will be managed by a Healthcare Network, they must also be informed about the type of care planned, that is to say, on the way they will be treated within the Network. The Network, its aims and its mode of operation must also be presented. The various actors involved and the healthcare circuit that the patient is about to enter must be clarified before obtaining consent. The patient must therefore agree to the care offered by the Network. The patient's wishes (to enter the Network or not) must be respected.

A law published at the end of 2002 concerning these Networks (Decree 2002-1463 of the $17^{\text {th }}$ December 2002 related to quality criteria, requirements for organization, functioning and assessment of Healthcare Networks, see Table I) made it compulsory to furnish written information for any care provided by a Network. Thus, upon entering a Network, the patient receives an information document explaining the services and the organisation of care offered by the structure. Furthermore, this document must be signed by the patient, his guardian, a representative of parental authority or a designated person etc.

Given the particular human and psychological distress related to the end of life $e^{1,2}$, a number of ethical issues arise from this requirement to provide written information and obtain written 
consent prior to palliative care. Healthcare professionals must take into account the fragility of the patient's psychological condition, when it comes to telling a patient the truth about the likely outcome.

Then two main problems concerning patients in palliative care must be discussed: ethical difficulties in providing information to terminal patients entering the palliative phase of a disease and the requirement for such patients to sign the information document.

1. Ethical difficulties in informing patients entering the palliative phase of a disease

Although oral information, which is essential, can often be complemented by information documents, written information seems inappropriate when patients enter a palliative care Network, as it means having to tell patients that they are in the palliative phase of their illness, or even revealing a diagnosis that doctors preferred not to give the patient, or that the patient did not wish to deal with ${ }^{3,4}$. This requirement does not take into account the fact that the passage from therapeutic to palliative care is always very progressive, with no real identifiable boundary. Furthermore, written information is by definition delivered in the same, stereotypical manner to all patients, making it impossible to take into account individual specificities.

The obligation to provide information relating to palliative care may therefore contradict the doctor's obligation to respect the patient's wish not to know the diagnosis or prognosis. It may also make it impossible to hide the patient's condition for his or her own good when the doctor considers that he or she is not ready to hear such information, which is contrary to the provisions of the French code of deontology. In some situations, such information may be interpreted by a patient who is not yet ready to hear it as the announcement of imminent death. That is why we consider that, in the case of palliative care, this legal obligation to inform patients contradicts medical practice, which, 
without wanting to hide the truth, requires time and precautions for the communication of information, particularly when that information concerns the end of the patient's life.

Moreover, as a patient can pass through different stages in the course of palliative care, the choice of therapy and medical techniques must be appropriate to the stage the patient is in, and the wishes of the patients can change. Thus, the informed consent collected at a particular time must be repeated at regular intervals so as to make it possible for the patient to change his or her mind at any moment. Thus, in palliative care, communication with the patient must be an ongoing process, and written information is ill-suited to this context.

2. Point and value of signing an information document for a patient at the end of life

In palliative care, because of the psychological state of the patient, the high level of asthenia or awareness problems due to the illness or the treatment, it is not always possible for the patient to formally sign the document.

From a medico-legal point of view, the signature of the document is contestable in such circumstances. Firstly, there is no proof that the person is capable of making an informed decision because of cognitive impairment.

Secondly, it does not necessarily indicate that the patient has really understood the information given and therefore the process in which they are engaged. Indeed, signing an information form merely indicates that the information has been received. This signature provides no information about the way in which the information was given or whether it was understood.

The question of the stage at which it is no longer reasonable to try to obtain the signature must be asked. There is no unequivocal answer and each case must be examined individually. It is 
undoubtedly for this reason that the law allows signature by a third party, a close friend, relative, confidant or guardian. If the patient is unconscious or has severely diminished awareness, it seems logical to seek the signature of a third party as specified in the law.

However, the problem choosing the person to sign the consent form arises when the patient was not able to and when he has not designated a third person. This chosen person must be a really close relative and must have put a lot of effort into caring for the patient. Moreover, the signature is not simply delegated consent; the signatory commits himself to accompanying the patient alongside the care professionals to the end of the patient's life.

Thus, healthcare professionals must be aware that the signature is a legal requirement but that it does not replace the need for the physician to build a close relationship with his patient and to listen to the patient attentively. Finally, in some situations, when there are no close relatives or caring persons, the doctor may choose not to have the document signed if he believes deep down that this would be inappropriate.

By way of conclusion, compulsory written information is not adapted to the practical realities of the physician-patient relationship in palliative care. Oral information must be preferred and the information document can merely be an educational medium for the patient and his family in order to complement oral explanations. 
Table I: Decree $2002-1463$ of the $17^{\text {th }}$ December 2002 related to quality criteria, requirements for organization, functioning and assessment of healthcare Networks, added to the French public health code as article D 6321-3

"The Network guarantees freedom to users to benefit from Network services or to withdraw. It also guarantees to users the freedom to choose the healthcare professionals involved in the Network.

The Network gives to users an information document which clarifies the functioning of the Network and the services it provides, the means employed to inform users at each step of care management, as well as the arrangements that guarantee to users access to information about their heath condition and the confidentiality of this information.

When individual care management is proposed by the Healthcare Network, the information document $(\ldots)$ is signed, when possible, by the user or, depending on the individual case, by a representative of parental authority, the guardian (...) or a designated person - a person of trust (...). This document also sets out the rules of management and the mutual obligations of the users and the healthcare professionals". 


\section{References:}

1 Cimino JE. A clinician's understanding of ethics in palliative care: an American perspective. Crit Rev Oncol Hematol 2003; 46:17-24.

2 Verhaak CM, Kraaimaat FW, Staps AC, van Daal WA. Informed consent in palliative radiotherapy: participation of patients and proxies in treatment decisions. Patient Educ Couns 2000; 41:63-71.

3 Yardley S, Davis C, Sheldon F. Receiving a diagnosis of lung cancer: patients' interpretations, perceptions and perspectives. Palliat Med 2001; 15:379-86.

4 De Haes $\mathrm{H}$, Koedoot $\mathrm{N}$. Patient centered decision making in palliative cancer treatment: a world of paradoxes. Patient Educ Couns 2003; 50:43-9. 